\title{
The effect of $\mathrm{SrTiO}_{3}$ seed and application of in-situ magnetic field on the preparation of $\mathrm{Pb}(\mathrm{Zr}, \mathrm{Ti}) \mathrm{O}_{3}$ thin film by pulsed laser deposition.
}

\author{
Naoki Wakiya*, Toyokazu Nagamune ${ }^{1}$, Ji-Won Moon ${ }^{1}$, Takanori Kiguchi ${ }^{2}$, Nobuyasu Mizutani ${ }^{3}$, \\ Hisao Suzuki ${ }^{4}$ and Kazuo Shinozaki ${ }^{1}$ \\ "Department of Material Science, Shizuoka University, 3-5-1 Johuku, Hamamatsu 432-8561, Japan \\ Fax: 81-53-478-1153, e-mail: tnwakiy@ipc.shizuoka.ac.jp \\ ${ }^{1}$ Department of Metallurgy and Ceramics Science, Tokyo Tech., 2-12-1 O-okayama, Meguro-ku, Tokyo 152-8550, Japan, \\ tnwakiy@ipc.shizuoka.ac.jp \\ ${ }^{2}$ Center of Advanced Materials Analysis, Tokyo Tech., 2-12-1 O-okayama, Meguro-ku, Tokyo 152-8550, Japan \\ ${ }^{3}$ Tokyo National College of Technology, 1220-2 Kunugida, Hachioji, Tokyo 193-0097, Japan \\ ${ }^{4}$ Graduate School of Science and Technology, Shizuoka University, 3-5-1 Johuku, Hamamatsu 432-8561, Japan
}

Polycrystalline $\mathrm{Pb}(\mathrm{Zr}, \mathrm{Ti}) \mathrm{O}_{3}$ thin film was prepared on $\mathrm{SrTiO}_{3} / \mathrm{Pt} / \mathrm{CeO}_{2} / \mathrm{SiO}_{2} / \mathrm{Si}$ substrate by pulsed laser deposition with in-situ magnetic field (Dynamic Aurora PLD method). $\mathrm{SrTiO}_{3}$ and $\mathrm{CeO}_{2}$ layers were also prepared by this method, and Pt layer (bottom electrode was prepared by if magnetron sputtering). Dynamic Aurora PLD method enabled to lower crystallization temperature for $\mathrm{CeO}_{2}$ (below $300{ }^{\circ} \mathrm{C}$, even at room temperature), $\mathrm{SrTiO}_{3}\left(400{ }^{\circ} \mathrm{C}\right)$ as well as $\mathrm{PZT}\left(400{ }^{\circ} \mathrm{C}\right) . \mathrm{CeO}_{2}$ layer was used to improve the crystallinity of $\mathrm{Pt}$ bottom electrode. $\mathrm{SrTiO}_{3}$ layer was used as a seed layer to help the crystallization of PZT. In case of $\mathrm{CeO}_{2}$, amorphous film was obtained without application of magnetic field. This indicates that application of magnetic field has the key to lower the crystallization temperature. Under $2000 \mathrm{G}$ of magnetic field, clear $\mathrm{CeO}_{2}(111)$ peak was observed. For $\mathrm{SrTiO}_{3}$, it was also found that the crystallinity of $\mathrm{SrTiO}_{3}$ changes with the atmosphere during deposition; the crystallinity is not necessarily high in $\mathrm{O}_{2}$ atmosphere and the crystallinity was high in $\mathrm{N}_{2} \mathrm{O}$ atmosphere. Similar effect was also observed on the preparation of PZT thin film. Since it is known that $\mathrm{N}_{2} \mathrm{O}$ decomposes into $\mathrm{N}_{2}$ and atomic oxygen, and the atomic oxygen is very active. Therefore, application of magnetic field in the $\mathrm{N}_{2} \mathrm{O}$ atmosphere would enhance the formation of atomic oxygen to lower crystallization temperature of $\mathrm{SrTiO}_{3}$ and $\mathrm{PZT}$ thin films.

Key words: PZT, $\mathrm{SrTiO}_{3}$, seed layer, Dynamic Aurora PLD

\section{INTRODUCTION}

Lead zirconate titanate $\mathrm{Pb}(\mathrm{Zr}, \mathrm{Ti}) \mathrm{O}_{3}$ ( $\mathrm{PZT}$ ) thin films have been intensively studied for use in ferroelectric random access memories (FeRAM) and microelectromechanical systems (MEMS) due to large remanent polarization and piezoelectric displacement [1] Recently, low-temperature preparation below $500{ }^{\circ} \mathrm{C}$ is important to achieve aluminum circuit wiring. However, to obtain a crystallized PZT film with good electrical properties, the process temperature could be higher than $500{ }^{\circ} \mathrm{C}$ because poor crystallinity of ferroelectric phase occurs and nonferroelectric second phase such as pyrochlore is metastable below $500{ }^{\circ} \mathrm{C}$ [2]. So far, there are a lot of investigations to lower the crystallization temperature by introducing seed layers [3-14]. Shimizu et al. $[3,14]$ reported that lead titanate is a good seed for polycrystalline PZT thin film deposition at $390{ }^{\circ} \mathrm{C}$. Takahashi et al. [4] and Funakubo et al.[5,12] prepared PZT films using $\mathrm{PbTiO}_{3}$ seed layer at $395-600^{\circ} \mathrm{C}$. The remanent polarizations ( $\mathrm{Pr}$ ) were reported to be as low as $5 \mu \mathrm{C} / \mathrm{cm}^{2}$. Recently, we have succeeded to prepare PZT thin film at $290{ }^{\circ} \mathrm{C}$ by MOCVD using pulsed laser deposition (PLD) prepared $\mathrm{SrTiO}_{3}$ seed layer [15]. The Pr value of the film was as high as $21.2 \mu \mathrm{C} / \mathrm{cm}^{2}$. However, in the film, $\mathrm{SrTiO}_{3}$ seed layer was deposited at $800{ }^{\circ} \mathrm{C}$. This means that the requirement of lowering deposition temperature is not necessarily satisfied.
Concerning the lowering of crystallization by PLD method, Kobayashi et al. [16] reported that epitaxial growth of $\mathrm{NiO}$ thin film was realized on $\mathrm{MgO}(001)$ substrate even at room temperature by application of magnetic field on the deposition. They named their apparatus as "Aurora method". In their work, $\mathrm{SmCo}_{5}$ permanent magnet was set in the vacuum chamber. Kobayashi et al. also found that the amount of activated species are increased by application of magnetic field to the plum (plasma) generated during PLD [17].

In this work, we examined the effect of magnetic field on the deposition of PZT thin film to achieve lowering crystallization temperature. However, it is well known that permanent magnet such as $\mathrm{SmCo}_{5}$ and $\mathrm{Nd}-\mathrm{Fe}-\mathrm{B}$ lose magnetization at around $150-300{ }^{\circ} \mathrm{C}$. As mentioned above, it is almost impossible to crystallize both PZT and seed layers below such low temperature. Therefore we have to develop a novel PLD apparatus that magnetic field during deposition is given by electromagnet. In this paper, we will report the newly designed PLD chamber. Since, magnetic field is generated by electrical current, it is easy to change the magnitude of magnetic field during deposition dynamically. Therefore the newly developed apparatus was named as "Dynamic Aurora PLD". Using the equipment, we succeeded to prepare polycrystalline PZT thin films on $\mathrm{SrTiO}_{3}$ seed layer deposited on $\mathrm{Pt} / \mathrm{CeO}_{2} / \mathrm{Si}$ substrates below $400{ }^{\circ} \mathrm{C}$. 
2. DEVELOPMENT OF DYNAMIC AURORA PLD Figure 1 shows schematic drawing of the Dynamic-Aurora PLD apparatus. In the chamber,

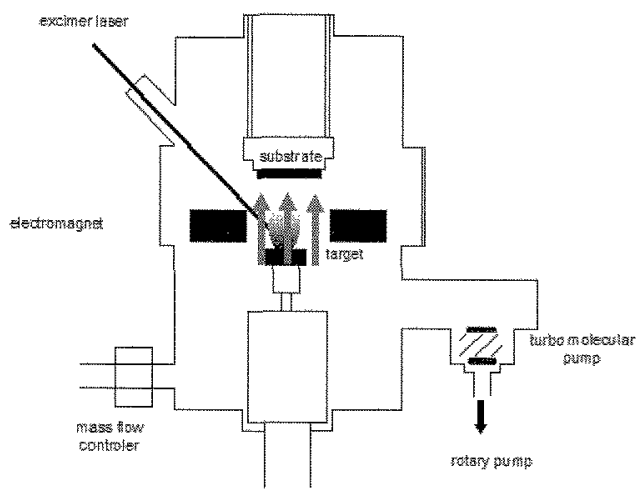

Fig. 1. Schematic drawing of dynamic aurora PLD apparatus. An electromagnet is installed between the target and the substrate.
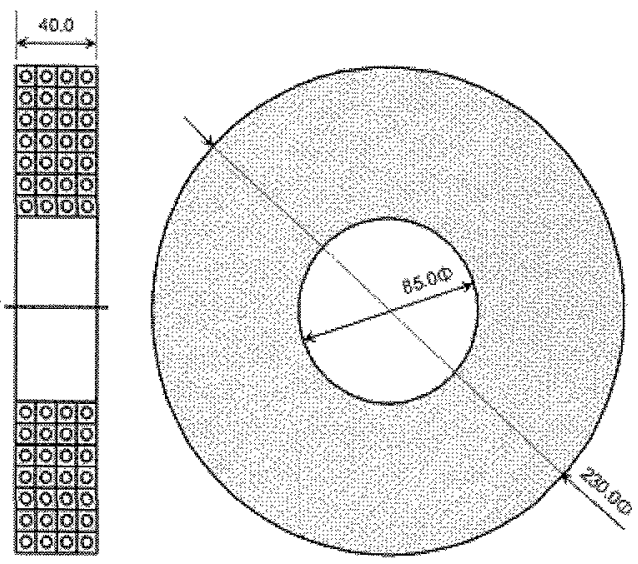

Fig. 2. Schematic drawing of solenoid coil installed in the vacuum chamber.

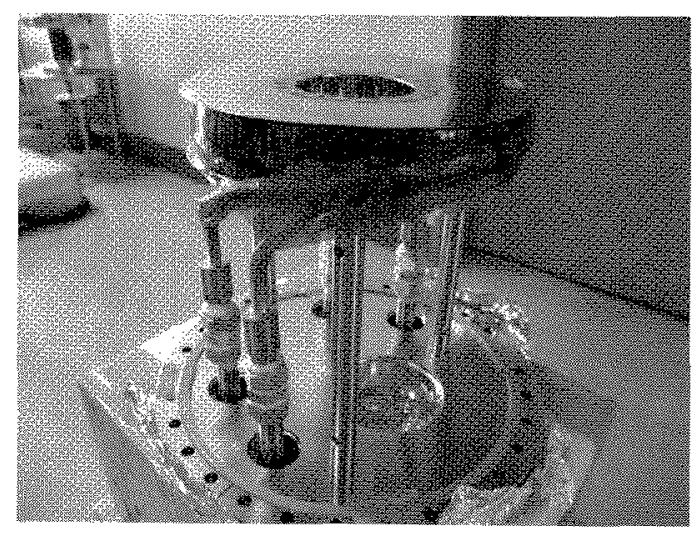

Fig. 3. Picture of the solenoid coil used in this work.

specially ordered solenoid coil ( 7 turns and 4 layers as shown in Fig. 2 and 3) was installed between the target and substrate to apply vertical magnetic field to the substrate; i.e., the direction of the magnetic field and the plume is parallel. The solenoid coil was consisted of a rolled hollow conductor (the cross-section area is
$10 \times 10 \mathrm{~mm}$ and the inside diameter of the hollow is 6 $\mathrm{mm}(\mathrm{p})$. The hollow conductor was covered with Kapton tape in order to isolate electrically. The diameters of outside and inside of solenoid coil were 230 and 85 $\mathrm{mm} \varphi$, respectively. Inside the hollow conductor, cooling water of around $7.8 \mathrm{l} / \mathrm{min}$ was poured. The thickness of the coil was $40 \mathrm{~mm}$. As the d.c. current source, three switching regulators (Takasago, UX-300T) was used as a parallel connection. Maximum electrical current for 1 switching regulator is $300 \mathrm{~A}$; therefore maximum electrical current for the system is 900 A. Figure 4 shows the relationship between electrical current and magnetic field up to $900 \mathrm{~A}$. This figure shows that magnetic field is proportional to the electrical current and maximum magnetic field is $2000 \mathrm{G}$. The fact that magnetic field is proportional to the current corresponds that the solenoid coil is air core, and magnetic flux is not saturated.

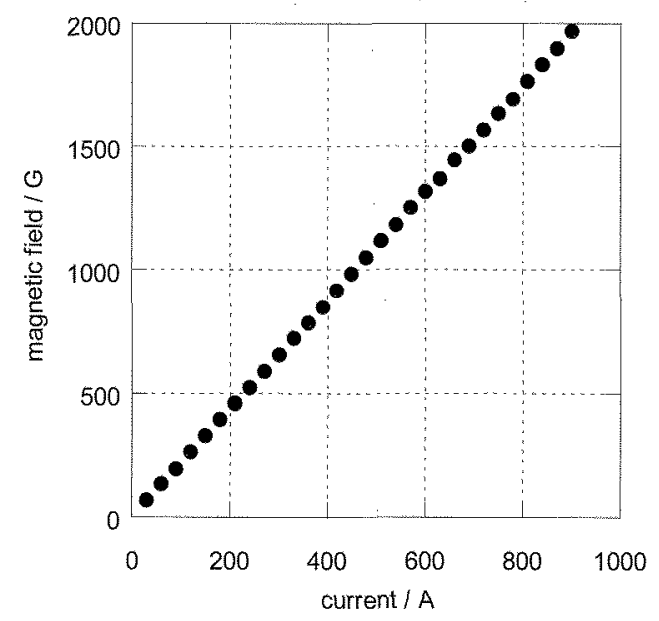

Fig. 4. Change of magnetic field with current for the solenoid coil shown in Figs. 2 and 3.

\section{EXPERIMENTAL}

$\mathrm{Si}(001)$ with natural oxide was used as the substrate. On the substrate, $35 \mathrm{~nm}$-thick $\mathrm{CeO}_{2}$ thin film was deposited by dynamic aurora PLD under $\mathrm{O}_{2}$ atmosphere. $\mathrm{CeO}_{2}$ layer was used to improve the crystallinity of $\mathrm{Pt}$ bottom electrode. $100 \mathrm{~nm}$-thick Pt bottom electrode was deposited by rf magnetron sputtering under $\mathrm{Ar}: \mathrm{O}_{2}=10: 1$ atmosphere with chamber pressure of 40 mtorr. On Pt bottom electrode, $0.8 \mathrm{~nm}$-thick $\mathrm{SrTiO}_{3}$ and $300 \mathrm{~nm}$-thick $\mathrm{Pb}\left(\mathrm{Zr}_{0.5} \mathrm{Ti}_{0.5}\right) \mathrm{O}_{3}$ (PZT) thin films were deposited by dynamic aurora PLD under $\mathrm{O}_{2}$ and $\mathrm{N}_{2} \mathrm{O}$ atmospheres. $\mathrm{SrTiO}_{3}$ layer was used as a seed layer to help the crystallization of PZT.

PLD was carried out by irradiation of focused $\mathrm{KrF}$ excimer laser (wavelength; $248 \mathrm{~nm}$ ) on the surface of ceramics targets. In the dynamic aurora PLD chamber pressure was changed between $1 \times 10^{-5}$ and $2 \times 10^{-2}$ torr. Magnetic field on the deposition was changed between 0 and $2000 \mathrm{G}$. Pt top electrode was fabricated through metal mask by d.c. magnetron sputtering. Film thickness and composition of the film was examined by wavelength dispersive $\mathrm{X}$-ray fluorescent spectroscopy (WDS, PW-2402, PANaytical). The thickness was also measured by surface profile meter (Dektak ${ }^{3}$, SLOAN). Crystal structure and rocking curve measurement was 
carried out by X-ray diffractometer (X'pert MPD, PANalytical). P-E hysteresis was measured by Sawyer-Tower circuit.

It should be noted that the deposition rate increased with the magnetic field, deposition time was changed to realize same thickness with and without magnetic field. This procedure was carried out for all films.

\section{RESULTS AND DISCUSSION}

4.1. The effect of magnetic field during deposition of $\mathrm{CeO}_{2}$ thin film on the crystallization

Figures 5(a) and (b) show XRD patterns of 30 nm-thick $\mathrm{CeO}_{2}$ thin films deposited at $300{ }^{\circ} \mathrm{C}$ under various oxygen pressures without and with magnetic field of $2000 \mathrm{G}$, respectively. These figure indicate that (111) orientation $\mathrm{CeO}_{2}$ thin films were grown on $\mathrm{Si}(001)$ substrate, and the crystallinity was increased with decreasing deposition pressure. It should be noted that application of magnetic field enhances the crystallinity of the film. Crystallization of $\mathrm{CeO}_{2}$ in the magnetic field was also observed even at room temperature deposition. So far, deposition of $\mathrm{CeO}_{2}$ at room temperature was reported by several authors [18-21]. However, to crystallize $\mathrm{CeO}_{2}$, post deposition annealing at 800-1000 ${ }^{\circ} \mathrm{C}$ was needed [18-20].
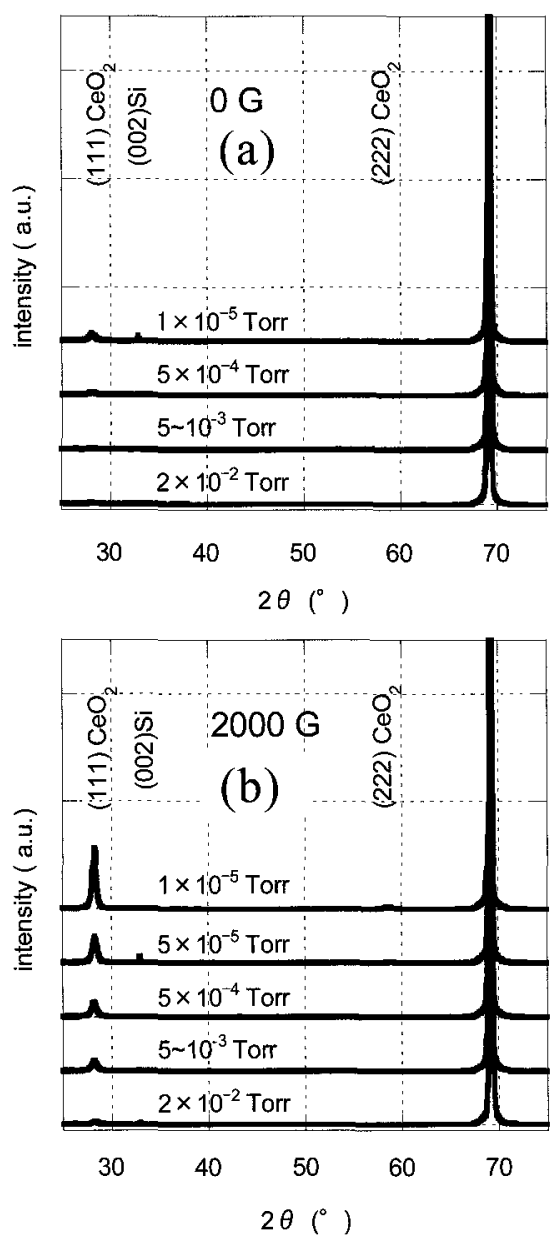

Fig. 5. XRD patterns of $\mathrm{CeO}_{2}$ thin film deposited on $\mathrm{Si}(001)$ substrate at $300{ }^{\circ} \mathrm{C}$ under various oxygen pressure; (a) without magnetic field, (b) with magnetic field of $2000 \mathrm{G}$.
Yoshimoto et al.[21] succeeded to prepare epitaxial grown $\mathrm{CeO}_{2}$ on $\mathrm{Si}(111)$ substrate at room temperature without post deposition annealing. However, ultra high vacuum (UHV) environment was needed for the crystallization. In this work, deposition pressure was as high as $1 \times 10^{-5}$ torr order. Therefore, this work suggests that crystallization of $\mathrm{CeO}_{2}$ at room temperature can be realized by application of magnetic field without using post deposition annealing and UHV atmosphere.

On the $\mathrm{CeO}_{2} / \mathrm{Si}$ substrates, $100 \mathrm{~nm}$-thick Pt film was deposited by rf magnetron sputtering at $300{ }^{\circ} \mathrm{C}$ under 40mtorr of $\mathrm{Ar}: \mathrm{O}_{2}=10: 1$ atmosphere. The Pt film had (111) orientation. Figure 6 shows change of full width half maximum (FWHM) of omega-scan (rocking curve measurement) of $\mathrm{CeO}_{2}$ films with oxygen pressure during deposition. In this figure the FWHM of Pt films deposited on $\mathrm{CeO}_{2}$ film (grown in the magnetic field) was also shown. This figure clearly shows that the crystallinity of $\mathrm{Pt}$ was determined by the crystallinity of $\mathrm{CeO}_{2}$ layer.

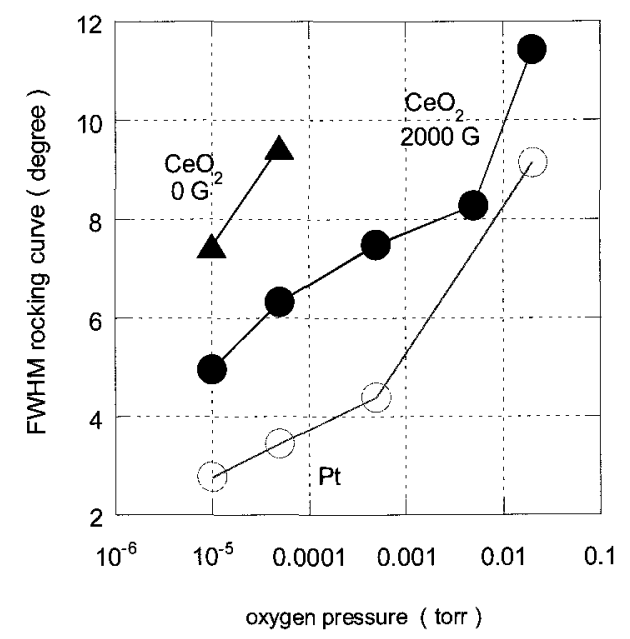

Fig. 6. Change of FWHM of omega-scan (rocking curve measurement) with oxygen pressure on the deposition of $\mathrm{CeO}_{2}$ film. The change of FWHM of Pt deposited on $\mathrm{CeO}_{2}$ layer was also shown for comparison.

\subsection{The effect of magnetic field during deposition of $\mathrm{SrTiO}_{3}$ thin film on the crystallization}

At first, $\mathrm{SrTiO}_{3}$ films were deposited on $\mathrm{Pt} / \mathrm{SiO}_{2} / \mathrm{Si}$ substrate to simplify the process parameter. $50 \mathrm{~nm}$-thick $\mathrm{SrTiO}_{3}$ films were deposited using stoichiometric $\mathrm{SrTiO}_{3}$ target and substrate temperature of $400{ }^{\circ} \mathrm{C}$ under various oxygen pressure with and without magnetic field Figure 7 shows the XRD patterns of $\mathrm{SrTiO}_{3}$ films. This figure indicates that crystallinity of the film was low regardless of the deposition conditions. Since trace $\mathrm{TiO}_{2}$ peak was detected for the film prepared with magnetic field of $2000 \mathrm{G}$, the change of composition by application of magnetic field was examined. The result was shown in Fig. 8. This figure indicates that $\mathrm{Ti} /(\mathrm{Sr}+\mathrm{Ti})$ ratio increases with magnetic field during deposition. When magnetic field is applied during deposition, Lorentz force work for the ionized species. In our configuration, the Lorentz force prevents to diffuse the plume and concentrate it toward the center of the substrate. Therefore, we presume that the change of 
composition by the magnetic field would be brought about by the degree of the influence of Lorentz force; the influence would be high for Ti but not so high for Sr. The reason is not so clear but a possibility is that $\mathrm{Sr}$ is heavier than $\mathrm{Ti}$.

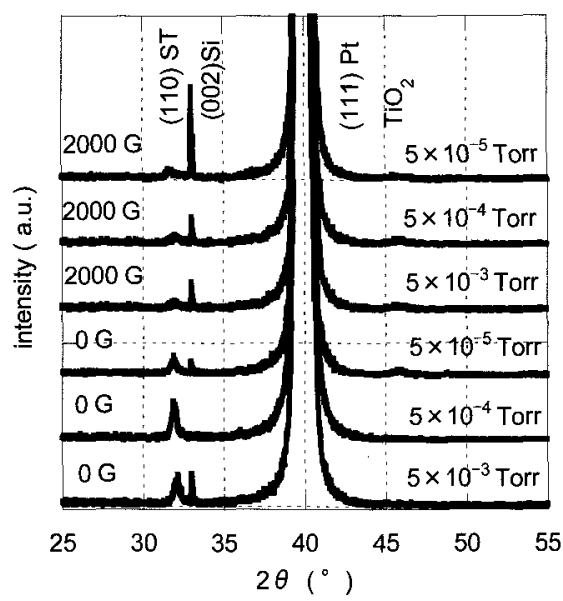

Fig. 7. Change of XRD patterns of $\mathrm{SrTiO}_{3}$ thin film deposited on $\mathrm{Pt} / \mathrm{SiO}_{2} / \mathrm{Si}$ substrate deposited at $400{ }^{\circ} \mathrm{C}$ under various oxygen pressure with and without magnetic field of $2000 \mathrm{G}$.

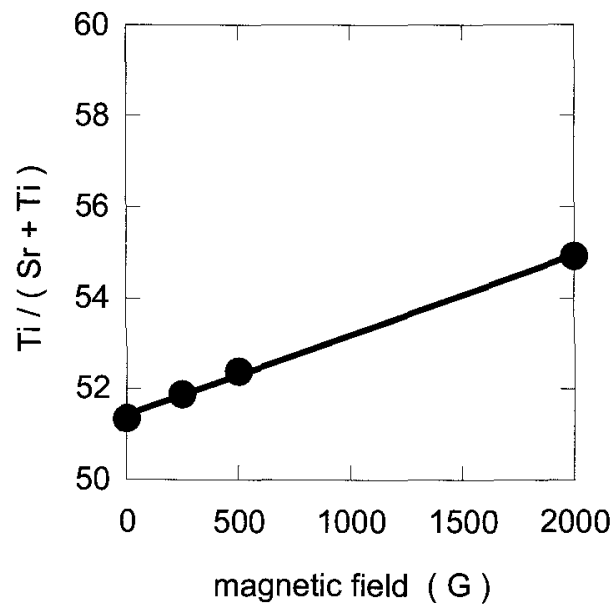

Fig. 8. Change of $\mathrm{Ti} /(\mathrm{Sr}+\mathrm{Ti})$ ratio with magnetic field when stoichiometic $\mathrm{SrTiO}_{3}$ was used as the target.

To adjust the composition, we prepared many targets having various $\mathrm{Ti} /(\mathrm{Sr}+\mathrm{Ti})$ ratio. As the result, it was found that stoichiometric $\mathrm{SrTiO}_{3}$ thin film was obtained when $\mathrm{Ti} /(\mathrm{Sr}+\mathrm{Ti})=0.45$ composition target was used at magnetic field of $2000 \mathrm{G}$. However, after the composition was adjusted to the stoichiometric one, the crystallinity was not improved very much at $400{ }^{\circ} \mathrm{C}$. Therefore the effect of $\mathrm{N}_{2} \mathrm{O}$ gas was examined. Figures 9 (a) and (b) show XRD patterns of $\mathrm{SrTiO}_{3}$ thin film deposited under various $\mathrm{N}_{2} \mathrm{O}$ pressure without and with magnetic field of $2000 \mathrm{G}$, respectively. These figure indicate that $\mathrm{SrTiO}_{3}$ thin film having high crystallinity was obtained under $\mathrm{N}_{2} \mathrm{O}$ pressure of $1 \times 10^{-2}$ torr. It was also found that the crystallinity was lowered when $\mathrm{N}_{2} \mathrm{O}$ pressure was $2 \times 10^{-2}$ torr. It is well known that dissociation of $\mathrm{N}_{2}$ and atomic oxygen occurs when $\mathrm{N}_{2} \mathrm{O}$ is decomposed. Atomic oxygen is very active and the active oxygen helps to form perovskite type structure even at $400{ }^{\circ} \mathrm{C}$. However, if the $\mathrm{N}_{2} \mathrm{O}$ concentration is too high, the active atomic oxygen would bring about etching during deposition; therefore, the formation of perovskite structure was disturbed.

The deposition condition of crystalline $\mathrm{SrTiO}_{3}$ thin film examined on the $\mathrm{Pt} / \mathrm{SiO}_{2} / \mathrm{Si}$ substrates was also applied to the $\mathrm{Pt} / \mathrm{CeO}_{2} / \mathrm{Si}$ substrates.

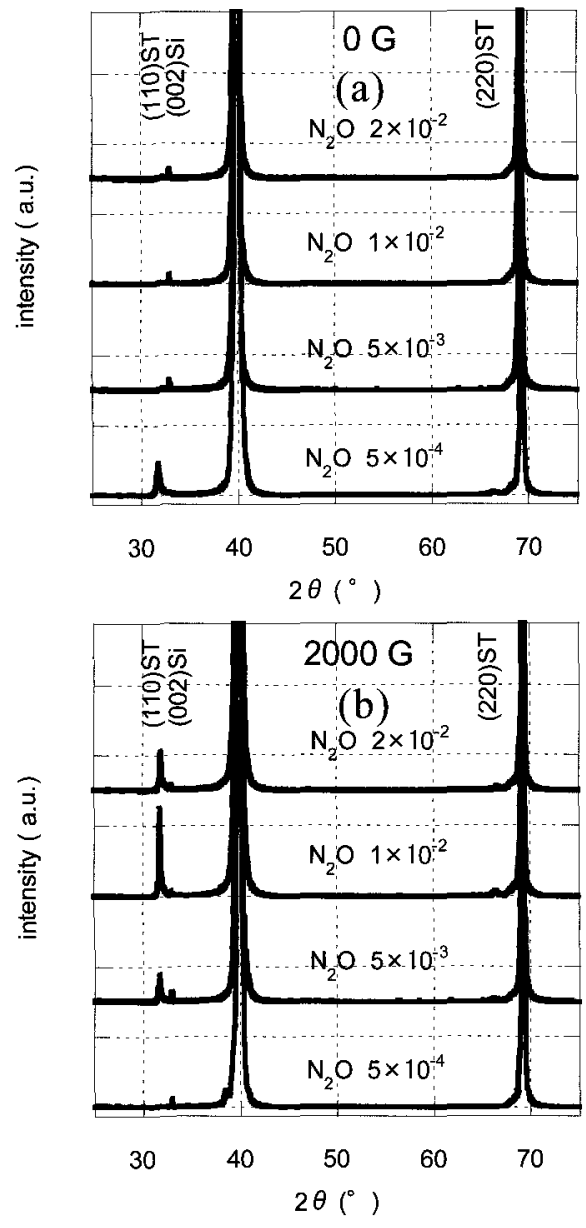

Fig. 9. XRD patterns of $\mathrm{SrTiO}_{3}$ thin film deposited on $\mathrm{Pt} / \mathrm{SiO}_{2} / \mathrm{Si}(001)$ substrate at $400{ }^{\circ} \mathrm{C}$ under various $\mathrm{N}_{2} \mathrm{O}$ pressure; (a) without magnetic field, (b) with magnetic field of $2000 \mathrm{G}$.

\subsection{The effect of magnetic field during deposition of PZT thin film on the crystallization}

$35 \mathrm{~nm}$-thick PZT thin film was deposited at $400{ }^{\circ} \mathrm{C}$ on $\mathrm{SrTiO}_{3} / \mathrm{Pt} / \mathrm{SiO}_{2} / \mathrm{Si}$ substrates. In the same way of $\mathrm{SrTiO}_{3}$, PZT thin film was deposited in $\mathrm{O}_{2}$ and $\mathrm{N}_{2} \mathrm{O}$ atmosphere with various pressures. Figures 10 (a)-(d) show XRD patterns of the PZT films deposited in $\mathrm{O}_{2}$ without and with magnetic field, and in $\mathrm{N}_{2} \mathrm{O}$ without and with magnetic field of $2000 \mathrm{G}$, respectively. These figures indicate that in $\mathrm{O}_{2}$ atmosphere, the effect of magnetic field is not so clear. However, in $\mathrm{N}_{2} \mathrm{O}$ atmosphere, strong PZT(101) peak was observed in the magnetic field. The intensity of diffraction of PZT was highest 

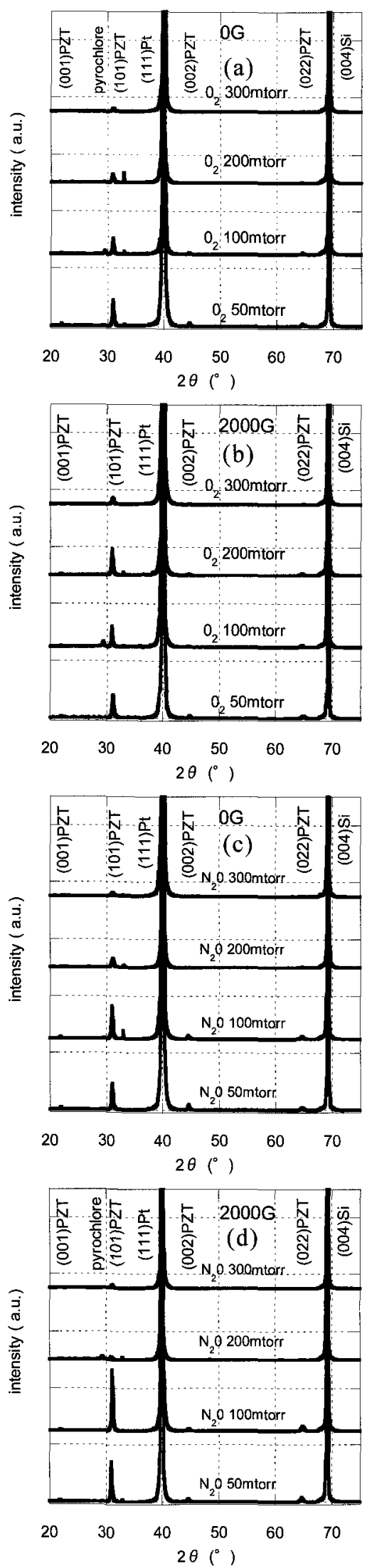

Fig. 10. XRD patterns of PZT deposited on $\mathrm{SrTiO}_{3} / \mathrm{Pt} / \mathrm{SiO}_{2} / \mathrm{Si}$ substrate; (a) in $\mathrm{O}_{2}$ at $0 \mathrm{G}$, (b) in $\mathrm{O}_{2}$ at $2000 \mathrm{G}$, (c) in $\mathrm{N}_{2} \mathrm{O}$ at $0 \mathrm{G}$, and (d) in $\mathrm{N}_{2} \mathrm{O}$ at $2000 \mathrm{G}$, respectively. when the $\mathrm{N}_{2} \mathrm{O}$ pressure was 100 mtorr, and decreases with increasing $\mathrm{N}_{2} \mathrm{O}$ pressure. This tendency is same with that of $\mathrm{SrTiO}_{3}$ shown in Fig. 9(b). These results indicate that polycrystalline PZT thin film having high crystallinity can be prepared below $400{ }^{\circ} \mathrm{C}$ by using magnetic field application during deposition and the use of $\mathrm{N}_{2} \mathrm{O}$ atmosphere. For the case of PZT, the composition of the film was unchanged with the application of magnetic field as shown in Table I. In the case of $\mathrm{SrTiO}_{3}, \mathrm{Ti} /(\mathrm{Sr}+\mathrm{Ti})$ ratio was increased with magnetic field as shown in Fig. 8. The reason why the change of composition does not occur in case of PZT is not clarified yet; however, it is expected that the degree of ionization would have the key since Lorentz force work on the ionized species.

Table I. Composition of PZT target and deposited thin film without and with magnetic field of 2000 . (atomic ratio).

\begin{tabular}{|c|c|c|}
\hline & $\mathrm{Pb} /(\mathrm{Pb}+\mathrm{Zr}+\mathrm{Ti})$ & $\mathrm{Zr} /(\mathrm{Zr}+\mathrm{Ti})$ \\
\hline PZT target & 0.500 & 0.520 \\
\hline $\begin{array}{c}\text { PZT thin film } \\
(0 \mathrm{G})\end{array}$ & 0.564 & 0.507 \\
\hline $\begin{array}{c}\text { PZT thin film } \\
(2000 \mathrm{G})\end{array}$ & 0.551 & 0.505 \\
\hline
\end{tabular}

To evaluate electrical property of PZT thin film prepared by this method, $\mathrm{PZT} / \mathrm{SrTiO}_{3} / \mathrm{Pt} / \mathrm{CeO}_{2} / \mathrm{Si}(001)$ structure film was prepared. For each layer, optimal deposition conditions were used. The thickness of each layer was PZT: $250 \mathrm{~nm}, \mathrm{SrTiO}_{3}: 0.8 \mathrm{~nm}, \mathrm{Pt}: 100 \mathrm{~nm}$, and $\mathrm{CeO}_{2}: 30 \mathrm{~nm}$. The prepared film was also polycrystalline. On the surface of the film, $100 \mu \mathrm{m} \varphi$ and $100 \mathrm{~nm}$ thick Pt top electrodes were prepared by dc sputtering through metal mask. The P-E hysteresis measurement shown in Fig. 11 shows that saturated P-E curve was observed. Observed remanent polarization (Pr) was $30.5 \mu \mathrm{C} / \mathrm{cm}^{2}$. This means that the use of dynamic aurora PLD is useful to lower crystallization temperature for $\mathrm{CeO}_{2}, \mathrm{SrTiO}_{3}$ and $\mathrm{PZT}$ films.

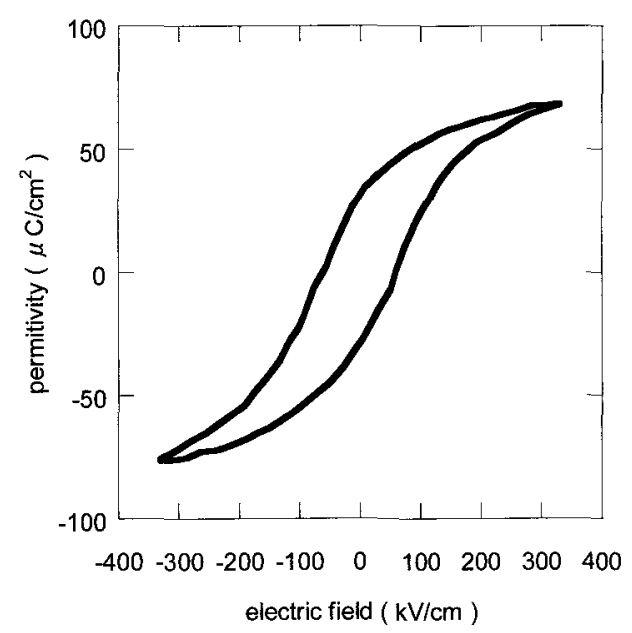

Fig. 11. P-E hysteresis curve of PZT thin film deposited at $400{ }^{\circ} \mathrm{C}$ on $\mathrm{SrTiO}_{3} / \mathrm{Pt} / \mathrm{CeO}_{2} / \mathrm{Si}(001)$ substrate. 


\section{CONCLUSIONS}

Dynamic aurora PLD apparatus that PLD chamber with electromagnet was developed. We have succeeded to prepare polycrystalline $\mathrm{PZT} / \mathrm{SrTiO}_{3} / \mathrm{Pt} / \mathrm{CeO}_{2} / \mathrm{Si}$ structure below $400{ }^{\circ} \mathrm{C}$. To achieve this structure, the condition to achieve crystalline $\mathrm{CeO}_{2}$ and $\mathrm{SrTiO}_{3}$ thin films below $400{ }^{\circ} \mathrm{C}$ was clarified. For $\mathrm{CeO}_{2}$, crystallization did not occur below $300{ }^{\circ} \mathrm{C}$ unless magnetic field of $2000 \mathrm{G}$ was applied. For $\mathrm{SrTiO}_{3}$, it was found that both application of magnetic field and using $\mathrm{N}_{2} \mathrm{O}$ atmosphere were important to obtain crystalline $\mathrm{SrTiO}_{3}$ below $400{ }^{\circ} \mathrm{C}$. Similar effect was also observed on the preparation of PZT thin film. It was suggested that application of magnetic field in the $\mathrm{N}_{2} \mathrm{O}$ atmosphere would enhance the formation of atomic oxygen to lower crystallization temperature of $\mathrm{SrTiO}_{3}$ and PZT thin films.

\section{References}

[1] D. L. Folk, F. A. Lepligard, and J. J. Kingston, $M R S$ Bull. 21.7, 53 (1996).

[2] H. Hu, L. Shi, V. Kumar, and S. B. Krupanidhi, Ceram. Trans. 25, 113 (1992).

[3] M. Shimizu, O. Mamoru, F. Hironori, and N. Hirohiko, Jpn. J. Appl. Phys., 41, 6686 (2002).

[4] K. Takahashi, T. Oikawa, K. Saito, M. Shimizu, and H. Funakubo, Jpn. J. Appl. Phys., 41, 6873 (2002).

[5] H. Funakubo, K. Tokita, T. Oikawa, M. Aratani, and K. Saito, J. Appl. Phys. 92, 5448 (2002).

[6] G. Asano, T. Oikawa, and H. Funakubo, Jpn. J. Appl. Phys., 42, 2801 (2003).

[7] D. J. Kim, J. P. Maria, A. I. Kingon, and S. K. Streiffer, J. Appl. Phys. 93, 5568 $\ulcorner 2003\rceil$.

[8] T. Okinawa, K. Takahashi, J. Ishida, Y. Ichikawa, T. Ochiai, K. Saito, A. Sawabe, and H. Funakubo, Integr. Ferroelectr. 46, 55 (2002).

[9] D. S. Kil, J. M. Lee, and J. S. Roh, Chem. Vap. Deposition, 8, 195 (2002).

[10] S. Baba, K. Numata, and S. Miyake, Sci. Technol. Adv. Mater. 1, 211 (2000).

[11] M. Shimizu, M. Sugiyama, H. Fujisawa, and T. Shiosaki, Jpn. J. Appl. Phys., 33, 5167 (1994).

[12] M. Aratani, T. Ozeki, and H. Funakubo, Jpn. J. Appl. Phys., 40, L343 (2001).

[13] H. C. Lee and W. J. Lee, Jpn. J. Appl. Phys., 40, 6566 (2001).

[14] M. Shimizu, M. Sugiyama, H. Fujisawa, and T. Shiosaki, Jpn. J. Appl. Phys., 33, 5167 (1994).

[15] J. W. Moon, S. Tazawa, K. Shinozaki, N. Wakiya, and N. Mizutani, Appl. Phys. Lett., 89, 202907 (2006).

[16] M. Tachiki, T. Hosomi, and T. Kobayashi, Jpn. J. Appl. Phys. 39, 1817 (2000).

[17] T. Kobayashi, H. Akiyoshi, and M. Tachiki, Appl. Surf. Sci. 197-198, 294 (2002).

[18] B.Hirchauer et al., Thin Solid Films, 348, 3 (1999).

[19] V.Trtik et al., J. of Crystal Growth, 192, 175 (1998).

[20] T.Amiet al., Appl. Phys. Lett., 78,10 (2001).

[21] M.Yoshimoto et al., Jpn. J. Appl. Phys., 34, 688 (1995).

\section{Acknowledgements}

This work was supported by Grants-in-aid from the Ministry of Education, Culture, Sports and Technology of Japan (16686040).

(Received December 29, 2006;Accepted January 5, 2007) 